\title{
Metáforas orientacionales y espacialización del sujeto en Una casa en la sombra, de Carlos López Degregori
}

\author{
Camilo Fernández Cozman \\ Universidad de Lima
}

\section{RESUMEN}

Sobre la base de los aportes de la lingüística cognitiva de George Lakoff y de Mark Johnson, y de los planteamientos de Michel Collot, María Lucía Puppo y Alicia Salomone, el autor analiza las metáforas orientacionales y la espacialización del sujeto en Una casa en la sombra, tercer poemario de Carlos López Degregori. Lakoff y Johnson distinguen las metáforas estructurales, ontológicas y orientacionales a partir de la idea de que el pensamiento humano es, en gran medida, metafórico. Collot señala cómo el poeta moderno proyecta su subjetividad en los espacios externos. Dicha noción es desarrollada por Puppo y Salomone con el fin de caracterizar el pacto del poeta con la modernidad.

Palabras clave: metáfora, orientacional, espacialización, sujeto

\section{ABSTRACT}

Based on the contributions of the cognitive linguistics of George Lakoff and Mark Johnson, and the approaches of Michel Collot, María Lucía Puppo and Alicia Salomone, the author analyzes the orientational metaphors and the spatialization of the subject in Una casa en la sombra, third book of poems by Carlos López Degregori. Lakoff and Johnson distinguish 
structural metaphors, ontological and orientational metaphors from the idea that human thought is, to a large extent, metaphorical. Collot points out how the modern poet projects his subjectivity in external spaces. This notion is developed by Puppo and Salomone in order to characterize the pact of the poet with modernity.

Keywords: metaphor, orientational, spatialization, subject

Durante mucho tiempo se pensó que la Retórica tenía como función principal la descripción de las figuras literarias como desvíos respecto de la norma establecida por el grado cero, límite hacia el cual tiende el discurso científico de carácter denotativo (Grupo $\mu$ 1987). En tal sentido la expresión "gotas del tiempo" era concebida como un desvío (écart) en relación con el enunciado "gotas de agua”. De esa manera, los estudios retóricos se concentraban en el abordaje de la elocutio y dejaban de lado la inventio y la dispositio: la metáfora, por ejemplo, era vista de modo aislado respecto de la estructura discursiva y del mundo de las ideologías. Así se desarrolló una Retórica restringida que olvidó la dimensión totalizante de la perspectiva aristotélica y que tenía, como algunos de sus más connotados representantes, a Pierre Fontanier y al Grupo de Lieja.

No obstante, la lingüística cognitiva, a partir de los años ochenta del siglo pasado, recusó la perspectiva antes planteada al subrayar que en el pensamiento científico existe el funcionamiento de metáforas y metonimias, entre otros recursos figurativos. George Lakoff y Mark Johnson (2003) publicaron Metaphors We Live By en 1980, texto que impulsó un cambio radical en el ámbito del estudio semántico. Ellos evidenciaron que el pensamiento humano es, en gran medida, metafórico. Frente a ciertos modelos estructuralistas (Grupo $\mu$ 1987) que analizaban la metáfora como el cambio del sentido de una palabra sobre la base de la sustitución de un significante por el otro, Lakoff y Johnson concibieron que la percepción no se da aislada de las otras y que, como es lógico, resulta pertinente realizar emparejamientos metafóricos en determinados contextos semánticos específicos. El ejemplo que ellos pusieron fue "la dis- 
cusión es una guerra”, una megametáfora que incluía una serie de metáforas específicas como las siguientes: “ataqué tus argumentos”, “tus argumentos son indefendibles” (2003: 4). Además, Lakoff y Turner estudiaron la metáfora poética distinguiendo estructuras como "la vida es un juego" o "las personas son plantas" (1989: 12-20). Su abordaje semántico mostraba de qué manera un conjunto de metáforas configuraba la estructura profunda de los poemas.

Lakoff y Johnson (2003) ordenan las metáforas en tres clases: las orientacionales, las estructurales y las ontológicas. Aquellas subrayan la organización espacial y se presentan en las siguientes expresiones: "le dieron de baja en el ejército", "caí en una honda depresión psicológica”, "subió hasta la cumbre del éxito”, “me dieron de alta”. Las estructurales tienen como propósito estructurar un concepto en relación con el otro, por ejemplo, en las oraciones "la noche es la muerte", "la vida es un viaje" o "la discusión es una guerra" se trata de pensar la noche, la existencia o la discusión en relación con otro concepto (4-5). En tal sentido, nuestro plan de vida es como un itinerario turístico, o los argumentos son concebidos como armas conceptuales que empleamos, metafóricamente, en una polémica con un adversario ideológico. Por su parte, las ontológicas precisan cómo las experiencias con objetos posibilitan cuantificarlas y categorizarlas; verbigracia, "la mente es una máquina” o "la inflación es una entidad” (Lakoff y Johnson 2003) para mostrar de qué manera nuestra mente no está operativa o cómo combatir la inflación que puede ser muy elevada.

Lakoff y Johnson (2003) también señalan que toda metáfora oculta y destaca algo. Así, cuando César Vallejo define a la madre como “muerta inmortal” (Vallejo 1991: 383), se hace evidente la manera como la madre vence a la muerte, es decir, adquiere el estatuto de ser eterna para constituir el ser que está en la cumbre desde el punto de vista valorativo para el poeta santiaguino. Asimismo, Lakoff y Johnson subrayan cómo la estructuración metafórica es siempre parcial porque la analogía se manifiesta sobre la base de algunos aspectos semánticos que ambos términos comparten. En la expresión “las teorías son edificios” (Lakoff y Johnson 2003: 52-53), 
la relación entre estas y los edificios se produce a través del hecho de que ambos deben poseer una base consistente; en cambio, se deja de lado que los edificios tienen ventanas y habitaciones en vista de que dicha característica no aparece en las teorías. Por ejemplo, en el verso de Jorge Manrique "Nuestras vidas son los ríos” (2011: 74), vemos que se privilegian ciertos componentes que comparten ambos elementos: la fluidez y el transcurrir, pues la existencia del ser humano discurre como si fuera el líquido en el cauce de un río. Sin embargo, no se enfatiza que los ríos tienen peces, pues esa particularidad no está presente en las vidas.

1. Una casa en la sombra en la producción poética de Carlos López Degregori

Una casa en la sombra (1994) es el tercer poemario de López Degregori, poeta peruano que, en los años setenta del siglo pasado, se distinguió tanto de la propuesta del grupo Hora Zero (que plantea el poema integral) como de la poética “orientalista” de José Watanabe, de la dicción coloquial de Abelardo Sánchez León y de la neovanguardia impulsada por Mario Montalbetti. Por su parte, López evidencia una lectura rigurosa de los poetas de los años cincuenta como Blanca Varela. Heredero de estos dos autores, se distancia del coloquialismo anglosajón y abraza un registro metafórico que tiene sus fuentes tanto en el Simbolismo francés ${ }^{1}$ como en el surrealismo y su revaloración del lenguaje onírico.

Vega subraya el carácter insular de la obra de López (2015: 103). No aparecen en esta última algunas características de los poetas de los años setenta como la visión del migrante, el prosaísmo o la urbe como ente enajenante (Fernández 2009: 61-71); más bien, se desarrolla la poética de la obra abierta (Eco 1985: 63-92) que implica la apertura del poema a un abanico de posibilidades interpretativas de acuerdo con la propuesta simbolista de Mallarmé y el papel activo

\footnotetext{
Léase su teoría de las correspondencias visible en "Vocales" de Arthur Rimbaud (1991: 114-117) y el "laboratorio lingüístico” de Stéphane Mallarmé (1998: 221), por ejemplo.
} 
que este último le asignaba al lector en el proceso de recepción de un poema. Cebrecos subraya que la poesía de López supone un alejamiento del yo autobiográfico para plantear una universalización de la experiencia humana (1995: 36-37). Ferrari considera que hay una oscilación, en el mundo representado por el poeta, entre la persona y el personaje, vale decir, entre aquel que escribe y el sujeto que termina siendo: hay un movimiento que va desde una personalización hasta alguien que se transforma frente al lector ofreciendo una imagen autónoma respecto del yo biográfico (1998: 11).

Desde el título, Una casa en la sombra revela la predilección del poeta por las metáforas orientacionales. La casa es el espacio desde donde el sujeto mira el mundo y construye su poética; por eso, se alude a lugares prohibidos, a ciénaga, corral, hotel, huerto y hasta a cama o mina o abismo. La casa constituye una de las metáforas más sugestivas. Bachelard remarca que la casa provee al sujeto de un cuerpo hecho de imágenes dispersas: "Porque la casa es nuestro rincón del mundo. Es (...) nuestro primer universo. Es realmente un cosmos. Un cosmos en toda la acepción del término" (1983: 34). Veamos dos características esenciales que han sido precisadas por el ensayista francés: 1) La casa es, con frecuencia, imaginada como un ser vertical; 2) Ella es concebida como si fuera un ser concentrado que incita a una conciencia de centralidad (Bachelard 1983: 48). ¿Cuáles son las implicancias de los dos rasgos antes mencionados? La casa remite a una oposición de tipo orientacional entre el sótano (asociada a la parte de abajo) y la guardilla (ventana que se encuentra por encima del tejado de cierta casa), vale decir, provee de una organización espacial desde el punto de vista cognitivo, es decir, una estructuración del mundo desde una óptica del conocimiento y de la experiencia cotidiana.

Una casa en la sombra se divide en tres partes sobre la base de la dinámica espacial: los lugares adquieren inusitada primacía. En la primera ("El talento y el poeta"), asoma la idea de esconder (léase reprimir en un espacio cerrado) el producto de la fabulación poética y la predilección por regresar al hotel Pascal, donde aparecen el exceso y lo dionisíaco: "Entonces volveré al hotel Pascal/ donde 
dos borrachines juran y se niegan” (López 1994:77). En la segunda ("Los lugares prohibidos"), la abuela (que personifica la ley) se instaura - desde el reino de la muerte — como la autoridad de la casa y establece mecanismos de prohibición: "La abuela dice que es mejor dormir:/ encadenar la furia/ con el vértigo" (López 1994: 85). En la tercera ("Una casa en la sombra”), se desarrolla la noción del riesgo del retorno al jardín (espacio impregnado de soledad y de hálito de muerte): "Riesgo de regresar a un jardín/ donde no acuden ya los parientes/ ni los perros" (López 1994: 111).

En un ensayo que analiza los lazos entre la poesía y el paisaje, Michel Collot (2005) desarrolla la noción de "espacialización del sujeto" para precisar un fenómeno que explica algunos rasgos de la poesía de la lírica moderna a partir de Charles Baudelaire hasta Mallarmé. Collot plantea que, particularmente en la escritura poética, el sujeto se proyecta en el mundo y el paisaje (2005: 43). Esta idea ha sido tomada por otros investigadores, ya que el paisaje surge de "un doble movimiento de proyección del sujeto hacia el mundo y de introyección de los objetos por parte de la conciencia" (Puppo y Salomone 2017: 66). En un texto poético, el afuera se encuentra adentro y el adentro, afuera; puesto que, a través de la instancia de la enunciación, se configura un espacio subjetivo desde donde habla un sujeto que se convierte en espacio. No se trata de un mero recurso estilístico de naturaleza formalista. La espacialización del sujeto es una estrategia discursiva que pone de relieve una típica orientación del pensamiento moderno, para el cual ya no resulta viable la distinción de índole cartesiana entre el aspecto mental (lo propiamente cognitivo, en términos actuales) y el corporal. Es pertinente recordar la expresión "Yo es otro" (Je est autre) de Rimbaud que implica un descentramiento del sujeto y la novedosa noción de poesía objetiva formulada por el autor de Una temporada en el infierno que pone en tela de juicio el yo centrado del subjetivismo romántico; así como señalar la idea de la desaparición ilocutiva del poeta formulada por Mallarmé que supone un cuestionamiento a toda lectura biografista de un poema y da primacía al trabajo con el lenguaje que realiza el poeta en la modernidad. Ello evidencia 
cómo la lírica moderna ya no opone la subjetividad a la objetividad al puro estilo racionalista y cartesiano (Puppo y Salomone 2017: 66-67), sino que fusiona "alteridad y exterioridad" en el sujeto (Collot 2005: 43). Es como si el paisaje se convirtiera en una suerte de proyección del estado de ánimo del hablante.

2. Metáfora y espacialización del sujeto en "Los irracionales" En los primeros versos de "Los irracionales" se observan las metáforas orientacionales:

Recorro viejos rostros

reinos

una vida adelante desbordando otro modo de conciencia

En diciembre

hoy resucitado

mes que para mí es una ciénaga

irreal

o triste o certero

no sabiendo decir

pero diciendo

te convoco aquí (López 1994: 98)

Sin duda, la metáfora predominante es "vivir es recorrer los cuerpos", concebidos como espacios con rostros (sinécdoques pars pro toto de cuerpos) atravesados por la vejez (léase la historia de dichos rostros). En tal sentido, el sujeto está determinado no solo por su caminata, sino a través de una dirección asumida: va hacia los reinos. Lakoff y Johnson (2003) examinan la concepción occidental de tiempo: el pasado está atrás; el presente, aquí; el futuro, adelante. El sujeto se autopercibe en un espacio desbordado, es decir, que sale de sus habituales límites conscientes para acceder a una vida que se ubica delante de él, casi como una prolongación de su cuerpo. A ello se añade el escandido de los versos que refuerza la significación antes enunciada: la palabra "reinos" se halla inclinada 
hacia la derecha y resalta su espacialización en el soporte del signo material porque, desde el punto de vista mallarmeano, los espacios en blanco de un poema cuentan como signos. Asimismo, la aliteración (rostros-reinos) refuerza, en el ámbito fónico, el significado del recorrido del sujeto.

Posteriormente, el hablante —en tanto heredero de Rimbaud que desacraliza la tradición cristiana en Una temporada en el infierno- desmitifica la celebración de la Navidad. Diciembre es "una ciénaga/ irreal”, afirma el locutor. Foucault (1992) dice que hay tres procedimientos externos de exclusión: lo prohibido; la oposición entre la locura y la razón; y la dicotomía entre lo verdadero y lo falso. El hablante, en el poema de López, pronuncia la palabra prohibida (vale decir, excluida) que se opone al sistema institucionalizado de carácter religioso: diciembre es un lodo irreal. Se duda de los fundamentos básicos del catolicismo entendido como religión hegemónica, pues el poeta cuestiona el ritual del nacimiento del redentor.

La verticalidad y centralidad de la casa (Bachelard 1983: 48) están presentes en la parte II de "Los irracionales":

Le faltará fuerza a mi poema

El don del genio A ti lector te faltará

Delinquiremos y siempre quedará pendiente la pregunta:

en qué lugar encerré mi adolescencia (López 1994: 99)

La metáfora orientacional "la adolescencia es un cuarto cerrado" supone que la vida es una casa y, por ello, el sujeto espacializa su subjetividad. No queda clara dónde está, con precisión, la casa del hablante: hay una imprecisión que evoca cómo se borran los recuerdos de la mente del locutor. Además, el empleo de una $\mathrm{A}$ mayúscula en el centro del segundo verso antes citado divide este último en dos partes desde el punto de vista espacial: la estructura hiperbática recalca una oposición entre el genio creador y el lector, quien no tiene este don. No constituye un mero recurso estilístico, sino que implica un proceso de espacialización de temple mallar- 
meano y una dimensión pragmática: el poema hace cosas (le da un lugar a cada palabra) y posee un aspecto performativo o realizativo (Ohmann 1987: 24). Lakoff y Johnson subrayan que:

We speak in linear order; in a sentence, we say some words earlier and others later. Since speaking is correlated with time and time is metaphorically conceptualised in terms of space, it is natural for us to conceptualize language metaphorically in terms of space. Our writing system reinforces this conceptualization (...). We know which word occupies the first position in the sentence, whether two words are close to each other or far apart, whether a word is relatively long or short (2003: 126).

Desde la óptica de la lingüística cognitiva, la linealidad de las palabras, una tras otra, implica una jerarquización de elementos y una determinada conceptualización. El tiempo es conceptualizado, muchas veces, en términos de espacio, particularidad que se evidencia en expresiones como "dentro de cinco días, iré a verte”, donde la preposición espacial dentro sirve para aludir a una acción que se desarrollará en el tiempo.

La espacialización del sujeto se produce a través de un viaje hacia la infancia:

El amor fue blanco

Picado de viruela

el amor fue un diente que perdí

$\mathrm{y}$ desde entonces

cuando estoy en el corral

o el huerto

contando mis inúmeras hermanas

le ofrezco la mejor

(López 1994: 99)

La subjetividad del hablante (a través de la imagen infantil del diente perdido y de la viruela) se proyecta en el espacio del corral y del huerto. Se trata de la representación del encierro, pero también el hablante articula esta con la noción de un huerto familiar donde el 
amor se asocia con la carencia y la enfermedad. Más adelante, la presencia de la noche - "Y no lo hallé entre los muslos/ aunque toda la noche vigilé” (López 1994: 99)— implica la inclusión de elementos oníricos debido a la oposición entre la vigilia y el sueño, o eros (el amor sinónimo de falta y privación) frente a thanatos - “Entierro un diente en el huerto" (López 1994: 99)—.

En la parte III de "Los irracionales", tenemos otra espacialización del sujeto, quien pierde el espacio de su infancia y es desterrado:

\section{Desterrado seas \\ del huerto del corral \\ te multipliques en anónimos testigos \\ se te pudra el diente de morder}

te remontes al horno

te rechacen

para ti no existe permanencia (López 1994: 100)

La metáfora orientacional (“el huerto del corral es la infancia”) permite comprender la noción de destierro que se asocia con el acto de alejarse y de sentirse casi arrojado en el mundo. Multiplicarse “en anónimos testigos” significa la fragmentación del sujeto, quien pierde la protección de la madre (se pudre el diente y ya no hay la posibilidad de "succionar") y se expone al rechazo de los otros. La estabilidad de la infancia se ha convertido en la fragilidad de una existencia. Además, el escandido de los versos destaca el verboide "succionar" inclinado hacia la derecha en el espacio de la página en blanco y funciona al lado de otra metáfora orientacional del calor: subir al fuego que antecede al rechazo colectivo.

El final del poema es muy ilustrativo porque es sinónimo de fracaso comunicativo: “debía cumplir los 32/ y me debía el triunfo del poema” (López 1994: 100). No se produjo dicho triunfo, sino la derrota: el hacer poesía conduce al desencanto. Sin embargo, los últimos versos configuran lo que Roland Barthes (1986) llamó la estética del suicidio aludiendo a la página en blanco mallarmeana: 
Prefiero el derrumbe de las cosas

Lo que no vale la pena es hablar (López 1994: 100)

Antes nos habíamos referido a la pragmática de la poesía, vale decir, el texto hace cosas. Aquí no solo dice que es necesario callarse, sino también que el poema realiza el acto de suspender el sentido explícito y desemboca en el espacio en blanco de la página. Es como si alguien dijera lo siguiente: "no vale la pena hablar, entonces dejo mi poema inconcluso para que el lector pueda interpretar activamente cuál es el sentido implícito de este último". No solamente se ha derrumbado el mundo, sino, sobre todo, la poesía como posibilidad de establecer una comunicación fluida entre el emisor y el receptor.

3. Metáfora orientacional y subjetividad en "Cementerio de perros"

Abordemos este poema:

Una tarde encontré siete perros muertos en la carretera.

Canté aspirando el aire, las moscas, la violencia

y supe que sería definitivo mi verano.

Cómo llegaron aquí.

No sé.

La sabiduría es siempre de los huesos.

Pero pronto cumpliré los 33 ,

me casaré y tal vez tenga siete hijos.

Y cuando llegue la tarde en que confluyan veranos, carreteras

y una mosca perfecta me recuerde

este cementerio de sol

cantaré de nuevo el triunfo de los perros. (López 1994: 78) 
Este poema trata sobre la muerte. La metáfora orientacional que preside el mismo es la siguiente: "la subjetividad es un cementerio". El sujeto se espacializa porque concibe su mundo interno como si este fuera el panteón de los perros. Además, intuye que algún día morirá, por eso, precisa que su verano podría ser el definitivo; sin embargo, el canto (léase: la poesía) abre la posibilidad de celebrar el triunfo del cuerpo sobre la muerte. La sabiduría pertenece a los huesos, es decir, a la estructura ósea que sostiene la materia corporal del ser vivo. En dicho contexto, el saber probabilístico adquiere primacía porque el hablante dice que quizá tenga hijos en algún momento o tal vez ello quede como una expectativa frustrada. Duda acerca de la posibilidad de dejar descendencia en este mundo. La personificación de la mosca (asociada a los cadáveres) es muy ilustrativa al respecto porque recordará al hablante un cementerio lleno de luz y, por ello, el sujeto proyecta su subjetividad en un panteón luminoso: el cuerpo, evocado por el canto o el poema, puede celebrar el triunfo sobre la muerte.

En Una casa en la sombra, las metáforas orientacionales permiten al sujeto concebir su modo de sentir en términos espaciales. Así se superan las fáciles dicotomías y, en tal sentido, lo interno pasa a proyectarse en lo externo. La subjetividad es una casa, un hotel (poema "Visitas al hotel Pascal") o un cementerio, por ejemplo. He ahí la riqueza y carácter sugestivo de la poesía de Carlos López Degregori.

Referencias bibliográficas

BACHelard, Gaston

1983 Poética del espacio. México, D.F.: Fondo de Cultura Económica

BARTHES, Roland

1986 El grado cero de la escritura seguido de Nuevos ensayos críticos. México, D.F.: Siglo XXI Editores. 
Cebrecos, Fermín

1995 “Qué puede uno en el límite conceder'. Una aproximación provisional a la poesía de Carlos López Degregori”. Humanitas. Revista de la Facultad de Psicología. 33, 17-75.

Collot, Michel

2005 Paysage et Poésie. Paris: José Corti.

Eco, Umberto

1985 Obra abierta. México D.F.: Planeta.

Fernández Cozman, Camilo

2009 Mito, cuerpo y modernidad en la poesía de José Watanabe. Lima: Cuerpo de la Metáfora Editores.

Ferrari, Américo

1998 “La poesía de Carlos López Degregori: Presencia de nadie, ser de nada”. En López Degregori, Carlos. Aqui descansa nadie. Lima: Comillo Blanco, 9-18.

Foucault, Michel

1992 El orden del discurso. Barcelona: Tusquets.

GRUPO $\mu$

1987 Retórica general. Barcelona: Paidós.

LAKOFF, George y Mark JoHnSON

2003 Metaphors We Live By. Chicago and London: University of Chicago Press. https://doi.org/10.7208/ chicago/9780226470993.001.0001

LAKOFF, George y Mark Turner

1989 More than Cool Reason. A Field Guide to Poetic Metaphors. Chicago and London: University of Chicago Press. https:// doi.org/10.7208/chicago/9780226470986.001.0001

López Degregori, Carlos

1994 “Una casa en la sombra”. En Lejos de todas partes. Lima: Universidad de Lima, 71-113.

Mallarmé, Stéphane

1998 Divagaciones. Seguido de prosa diversa/correspondencia. Traducción y prólogo de Ricardo Silva-Santisteban. Lima: Pontificia Universidad Católica del Perú. 
MANRIQUe, Jorge

2011 Obras completas. Buenos Aires: Gradifco.

OHMANN, Richard

1987 Los actos de habla y la definición de la literatura. En Pragmática de la comunicación literaria. Ed., José Antonio Mayoral. Madrid: Arco/Libros S.A., 11-57.

Puppo, María Lucía y Alicia Salomone

2017 “Para entrar a una misma’: la espacialización de la subjetividad en la poesía de Julia de Burgos”. Anclajes. XXI, 3, 61-76. https://doi.org/10.19137/2017-2135

Rimbaud, Arthur

1991 Poesías. 2da. edición. Edición bilingüe. Trad. y notas, Juan Abeleira. Madrid: Hiperión.

1992 Una temporada en el infierno. 3ra. edición. Edición bilingüe. Trad. y ed., Ramón Buenaventura. Madrid: Hiperión.

VAllejo, César

1991 “Obra poética”. En Obras completas, tomo 1. Edición crítica, prólogo, bibliografía e índices de Ricardo González Vigil. Lima: Banco de Crédito del Perú.

Vega JÁcome, Selenco

2015 Del agua a la espesura del bosque. La poesía de Carlos López Degregori. Lima: Dedo Crítico Editores.

Recibido: $26 / 12 / 2017$

Aceptado: 27/04/2018 